\title{
Long-range epigenetic silencing at 2 q 14.2 affects most human colorectal cancers and may have application as a non-invasive biomarker of disease
}

\author{
R Mayor ${ }^{1,2}$, L Casadomé ${ }^{3}$, D Azuara ${ }^{3}$, V Moreno ${ }^{3}$, SJ Clark ${ }^{4}$, G Capellà ${ }^{3}$ and MA Peinado ${ }^{*, 1,2}$ \\ 'Institut de Medicina Predictiva i Personalitzada del Càncer (IMPPC), Badalona, Catalonia, Spain; ${ }^{2}$ Institut d'Investigació Biomèdica de Bellvitge (IDIBELL), \\ L'Hospitalet, Catalonia, Spain; ${ }^{3}$ Institut Català d'Oncologia (ICO), L'Hospitalet, Catalonia, Spain; ${ }^{4}$ Cancer Program, Garvan Institute of Medical Research, \\ Sydney, Australia
}

\begin{abstract}
Large chromosomal regions can be suppressed in cancer cells as denoted by hypermethylation of neighbouring CpG islands and downregulation of most genes within the region. We have analysed the extent and prevalence of long-range epigenetic silencing at $2 q \mid 4.2$ (the first and best characterised example of coordinated epigenetic remodelling) and investigated its possible applicability as a non-invasive diagnostic marker of human colorectal cancer using different approaches and biological samples. Hypermethylation of at least one of the CPG islands analysed (ENI, SCTR, INHBB) occurred in most carcinomas (90\%), with ENI methylated in 73 and $40 \%$ of carcinomas and adenomas, respectively. Gene suppression was a common phenomenon in all the tumours analysed and affected both methylated and unmethylated genes. Detection of methylated ENI using bisulfite treatment and melting curve (MC) analysis from stool DNA in patients and controls resulted in a predictive capacity of, $44 \%$ sensitivity in positive patients (27\% of overall sensitivity) and $97 \%$ specificity. We conclude that epigenetic suppression along 2 q 14.2 is common to most colorectal cancers and the presence of a methylated ENI CPG island in stool DNA might be used as biomarker of neoplastic disease.
\end{abstract}

British Journal of Cancer (2009) I 00, I534- 1539. doi:I0.1038/sj.bjc.6605045 www.bjcancer.com

Published online 21 April 2009

(c) 2009 Cancer Research UK

Keywords: DNA methylation; epigenetic silencing; CpG island hypermethylation; diagnostic marker; colorectal cancer; gene silencing; prognostic marker

In mammals, DNA methylation is an epigenetic modification that mainly occurs in the cytosine residue within the CpG dinucleotide, which is underrepresented along the genome. We also find short stretches of CpG-dense DNA, called CpG island, normally free of methylation and frequently associated with the $5^{\prime}$ promoter of many housekeeping or tissue-specific genes (Feinberg and Tycko, 2004; Baylin, 2005; Esteller, 2007a). Promoter CpG islands can become de novo methylated in a cancer cell leading to silencing of the associated gene (Baylin, 2005; Esteller, 2007a). Epigenetic inactivation of tumour suppressor genes is a well-characterised mechanism that is found in virtually all types of neoplasms. Many genes that are silenced by promoter hypermethylation in tumours play important roles in carcinogenesis; these include genome stability, cell-cycle entrance, proliferation, apoptosis, etc. (Baylin, 2005; Esteller, 2007a). The analysis of these epigenetic alterations has multiple applications including their use as prognostic factors, early disease markers, and predictors of response to therapy (Laird, 2003; Baylin, 2005; Esteller, 2007a).

* Correspondence: Dr MA Peinado, Institut de Medicina Predictiva i Personalitzada del Càncer (IMPPC), Ctra. Can Ruti, Camí de les Escoles s/n, 08916 Badalona, Barcelona, Spain;

E-mail: map@imppc.org

Received 22 December 2008; revised 12 March 2009; accepted 25 March 2009; published online 21 April 2009
Studies to date, using either candidate gene approaches or global surveys have shown that multiple, but discrete CpG islands can be methylated concurrently in any one cancer (Laird, 2003). In a recent study, a genome-wide DNA methylation screening approach showed coordinated hypermethylation of multiple $\mathrm{CpG}$ islands spanning a $1 \mathrm{Mb}$ region in colorectal cancer (Frigola et al, 2006). It is interesting that, hypermethylation of these $\mathrm{CpG}$ islands was accompanied by long-range epigenetic silencing (LRES) of a $4-\mathrm{Mb}$ chromosomal region mapping at $2 \mathrm{q} 14.2$ affecting all the genes regardless of whether their promoters were associated with $\mathrm{CpG}$ islands and if these were methylated or not (Frigola et al, 2006). Beyond this first evidence supporting, the existence of a new mechanism of gene inactivation in cancer, later studies indicate that LRES may also occur in other chromosomal regions and cancers (Stransky et al, 2006; Hesson et al, 2007; Hitchins et al, 2007; Rodriguez et al, 2008). This region encompasses the Engrailed-1 (EN1) gene encoding a homeobox transcription factor. EN1 plays a major role in development and upon deregulation in neoplasia (Bachar-Dahan et al, 2006; Rauch et al, 2007).

This work aims to determine the extent and prevalence of gene silencing in the chromosomal region $2 \mathrm{q} 14.2$ in human colorectal cancer and its possible association with the clinicopathological features of the tumours. We have also investigated the utility of one of the hypermethylated genes (EN1) as a diagnostic marker in stool and serum DNA samples of colorectal cancer patients. 


\section{MATERIALS AND METHODS}

\section{Samples}

A series of 108 patients pre-operatively diagnosed as having colorectal cancer and operated upon with curative or palliative intention between 1996 and 1998 at the Ciutat Sanitària i Universitària de Bellvitge was used. This series was part of a larger collection of patients prospectively included in a study designed to evaluate the prognostic value of genetic and epigenetic alterations (Gonzalez-Garcia et al, 2000; Vendrell et al, 2005). DNA methylation profiles were analysed in all 108 tumours and their normal tissue counterpart. A subgroup of 17 carcinomas were microdissected and the tumour infiltration front with $>75 \%$ tumour cell content, as assessed by visual examination of hematoxylin-eosin stained preparations, was selected for gene expression analysis. Special care was taken to discard areas with necrotic tissue or harbouring a highinflammatory component. Clinicopathological information was available for 91 cases (see Supplementary Table 1). Mean followup was $79.9 \pm 20.3$ months. Additionally, 10 colorectal adenomas were obtained from the Hospital de la Santa Creu i Sant Pau (Barcelona, Spain). In all cases, surgical specimens were collected in the operating room and immediately taken to the Pathology Department in ice. Carcinomas and paired normal samples were snap frozen within $2 \mathrm{~h}$ after removal and then stored at $-80^{\circ} \mathrm{C}$.

To study EN1 methylation as a diagnostic marker in colorectal cancer a different series of 30 patients with available DNA from normal and tumour tissues, stool and serum was used. Additionally, stool and serum DNA was available from 30 healthy donors matched by age and sex with the patient group. Stool DNA was extracted from cellular material obtained after centrifugation of bowel lavage or solid stools as described earlier (Puig et al, 1999). Serum DNA was obtained as described earlier (Castells et al, 1999).

The study protocol was approved by the Ethics Committee. No chemo- or radiotherapy was given prior to surgery. DNA and RNA amenable for genetic analyses were obtained using standard procedures.

\section{DNA methylation analysis}

Bisulfite sequencing Bisulfite conversion was carried out using $2 \mu \mathrm{g}$ of DNA for $16 \mathrm{~h}$ at $55^{\circ} \mathrm{C}$ under conditions described earlier (Stirzaker et al, 2004). A nested PCR was carried out in all cases to obtain a fragment of each one of the CpG islands to be analysed (see primer sequences in Supplementary Table 2). Bisulfite sequencing was carried out using the BigDye Terminator cycle sequencing kit (Applied Biosystems, Carlsbad, CA, USA). The degree of methylation was calculated by comparing the peak height of the cytosine signal with the peak height of the cytosine plus thymine signal as described (Melki et al, 1999).

Real-time PCR temperature dissociation (melting curve (MC)) Bisulfite conversion and PCRs were carried out as for bisulfite sequencing, except for the nested PCR, that was carried out using a Light Cycler 2.0 (Roche, Mannheim, Germany) and the Fast Start DNA Master Sybr Green I mix (Roche) with real-time detection as described (Frigola et al, 2006). Melting curves (MC) from fully unmethylated samples (as determined by bisulfite sequencing) were used as controls.

Methylation specific PCR (MSP) Bisulfite conversion and PCRs were carried out as for bisulfite sequencing, except for the nested PCR, which was carried out using specific primers for methylated and unmethylated DNA (Supplementary Table 2).

\section{Gene expression analysis}

cDNA was obtained by retrotranscription of $500 \mathrm{ng}$ of RNA with M-MLV retrotranscriptase (Invitrogen, Carlsbad, CA, USA) using random hexamers (Amersham Biosciences, Chalfont St Giles, UK) at $37^{\circ} \mathrm{C}$ for $1 \mathrm{~h}$. cDNA levels were quantified using the Light Cycler 2.0 real-time PCR system with Fast Start Master SYBR Green I kit (Roche). For a $10 \mu \mathrm{l}$ PCR reaction volume, $1 \mu \mathrm{l}$ of cDNA and $9 \mu$ l of mastermix were added to each capillary. Mastermix was prepared to a final concentration of $3.5 \mathrm{mM} \mathrm{MgCl} 2$ and $0.5 \mu \mathrm{M}$ of each primer. Primers used for expression analysis are listed in Supplementary Table 3.

\section{Statistical analysis}

All results are expressed as a mean \pm s.d. Statistical differences between variables were analysed with unpaired/paired $t$-tests or analysis of variance (ANOVA), as appropriate. Contingency tables were analysed by the $\chi^{2}$ or Fisher's-exact test. Survival curves were traced according to the Kaplan-Meier method. The statistical significance between survival curves was tested using the log-rank test. All $P$-values are calculated from two-sided statistical tests.

\section{RESULTS} Frequency and extent of 2q14.2 CpG island methylation
in human colorectal carcinomas and adenomas

The three CpG islands associated with the promoter region of the genes EN1, SCTR and INHBB mapping to 2q14.2 have been identified earlier to be hypermethylated in colorectal cancer (Frigola et al, 2006). These islands have been characterised by direct bisulfite sequencing and MC analysis in an extended series of 108 colorectal carcinomas with their paired normal tissue and in 10 adenomas. Two more $\mathrm{CpG}$ islands corresponding to genes PTPN4 and RALB were also analysed but remained unmethylated in all the normal and tumour samples (data not shown). An excellent agreement between results obtained by bisulfite sequencing and MC analysis was observed. Illustrative examples of nonmethylation, and partial and full methylation are shown in Supplementary Figures 1 and 2. Methylation of any of the CpG islands analysed was very rare in normal colon mucosa (only three cases; Supplementary Table 4) and always appeared as a low percentage of methylated molecules. Clonal analysis of normal and tumour samples with partial methylation showed the coexistence of densely methylated with poorly methylated molecules in all cases, confirming the presence of cell populations with heterogeneous DNA methylation profiles (data not shown). On the other hand, most carcinomas (82 out of 91, 90\%) exhibited methylation of at least one gene (Supplementary Figure 3A), with EN1 as the most frequently methylated gene in both carcinomas ( 66 out of 90 , $73 \%$ ) and adenomas (4 out of 10, $40 \%$ ); SCTR also presented a high level of methylation in carcinomas (48 out of 90,53\%) and adenomas (3 out of 10,33\%); whereas INHBB showed the lowest rate of methylation (23 out of 91 carcinomas, $25 \%$, and none of the 10 adenomas) (Figure 1 and Supplementary Table 4).

The methylation status of three additional CpG islands (CpG104, CpG 41 and $\mathrm{CpG}$ 173) flanking the EN1 CpG island (CpG128) (see Supplementary Figure 3B) was determined in a subset of 23 colon carcinomas and their matched normal mucosa from the series of 108 cases by PCR MC analysis. For each gene, a subset of $50 \%$ of the samples were re-analysed by bisulfite sequencing and all results were confirmed. As expected, none of the normal mucosa samples exhibited methylation in any of the six $\mathrm{CpG}$ islands analysed. In this subgroup, SCTR CpG island (CpG67) was the most frequently methylated (21 out of $23,91 \%$ ), followed by CpG173 (20 out of $23,87 \%$ ) and EN1 (17 out of $23,74 \%$ ) (Supplementary Figure 3C). The methylation status was independent for all the CpG islands analysed (data not shown) and no correlation between the methylation frequency and $\mathrm{CpG}$ island 

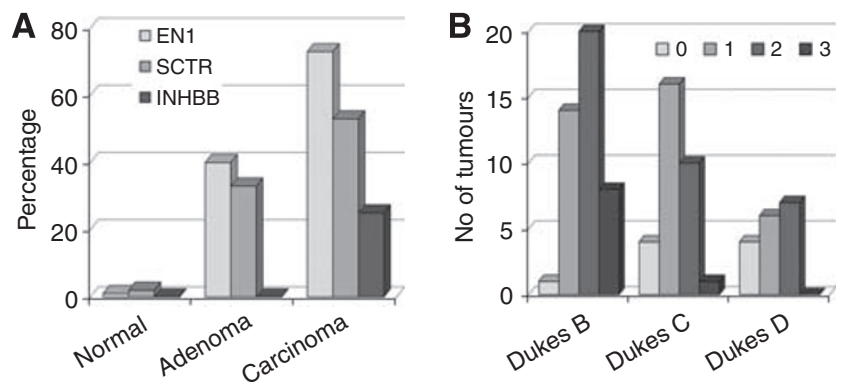

Figure I DNA methylation across $2 q / 4.2$ in colorectal cancer (A) Frequencies of the methylation in ENI, SCTR and INHBB CpG islands in normal colonic mucosa, and colorectal adenomas and carcinomas. $Y$-axis indicates the percentage of samples with methylation for each gene. (B) Incidence of methylation in colorectal carcinomas according Dukes' stage. $Y$-axis indicates the number of tumours exhibiting methylation in 0,1 , 2 or 3 of the CpG islands analysed (ENI, SCTR and INHBB).

size, $\mathrm{CpG}$ content, $\mathrm{G}+\mathrm{C}$ content, or $\mathrm{CpG}$ observed/expected ratio was observed.

\section{Genes at 2 q14.2 are down-regulated in most colorectal tumours}

To get insights into the extent of the gene suppression and its association with promoter hypermethylation, we analysed by real-time PCR the expression of eight genes mapping to $2 \mathrm{q} 14.2$ region in an independent series of 17 colorectal tumour samples and their matched normal pairs. Tumour tissues were microdissected to minimise the presence of non-tumour cells in the sample. The methylation state of five of the eight genes was determined using the MC analysis. EN1 expression was undetectable in all the samples. In agreement with earlier observations in pooled samples (Frigola et al, 2006), most of the genes were downregulated in all the tumours as compared with their paired normal mucosa (Figure 2). Interestingly, suppression affected the genes with methylatable CpG island (SCTR and INHBB) irrespective of its methylated state, genes with unmethylated CpG island (PTPN4, RALBB, TSN), and genes without CpG island (GLI2, MARCO). These results indicate that epigenetic suppression of the region is a very frequent event in colorectal cancer and suggest that DNA hypermethylation of some of the CpG islands is a secondary manifestation of the silencing.

\section{Genetic and clinicopathological features of the colorectal tumours with and without methylation in EN1, SCTR and INHBB}

Next, we wondered whether the methylation status of each one of the CpG islands analysed might be associated with genetic and clinicopathological characteristics of colorectal cancer patients. Sex, Dukes' stage, age, tumour localisation, the presence of mutations in the p53 and K-ras genes and microsatellite instability (MSI), and follow-up parameters were considered together with the methylation status of the EN1, SCTR and INHBB CpG islands in the series of 91 patients. Early stage tumours showed a higher proportion of methylated genes $(P=0.020)$ (Figure 1B and Supplementary Table 1) and SCTR was the gene exhibiting the higher differences $(P=0.015)$. In a subset of 50 of the 91 cases, chromosome profiles determined by comparative genomic hybridisation were available (Vendrell et al, 2007). No associations with specific chromosomal aberrations or with global indicators of chromosomal instability were observed. Regarding disease outcome, the number of methylated genes did not seem to modify the survival rate (data not shown). At the single gene level, patients with
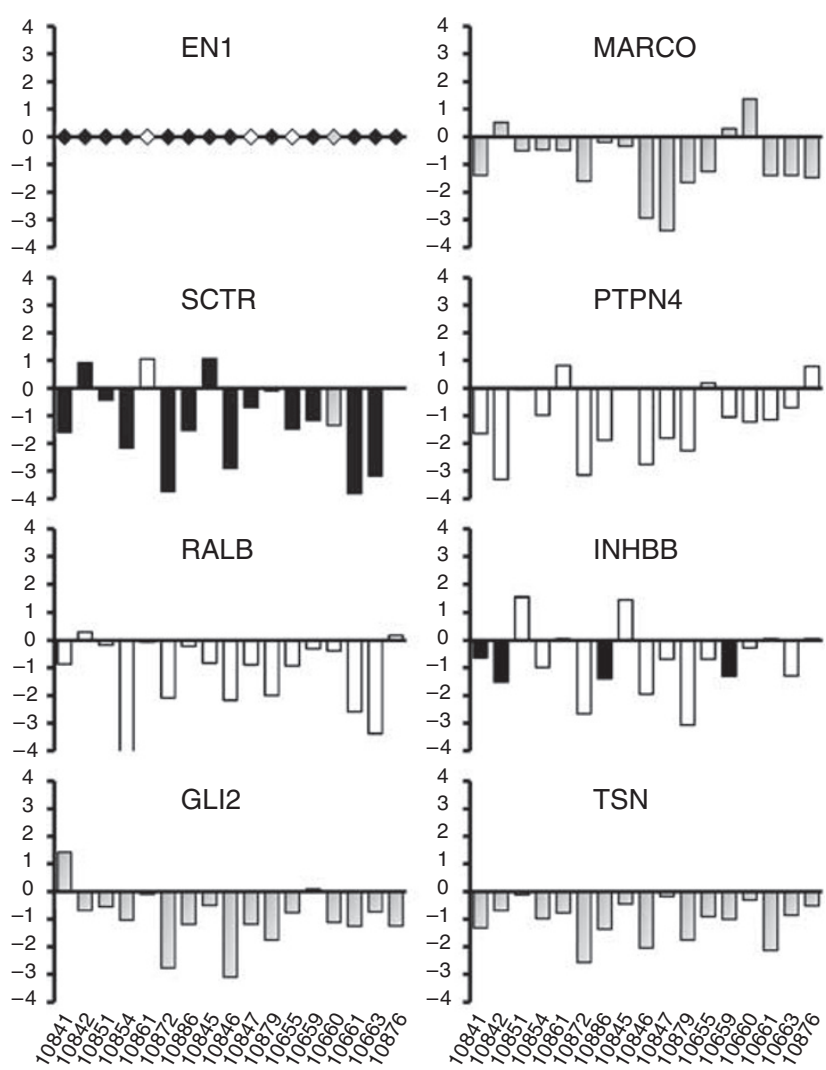

DNA methylation status: [Unmethylated Methylated [Not analysed $\diamond$ Undetectable expression values

Figure 2 Relative expression levels of the eight genes analysed across the 2 q 14.2 chromosome region in 17 colorectal tumour tissues and their paired normal mucosa. The log2 of the tumour/normal ratio is represented. Negative values indicate downregulation in the tumour as compared with the respective normal tissue. Expression levels were normalised using the I 8S rRNA expression as control. Methylation status was determined using melting curve (MC) analysis and is depicted in column filling as indicated Grey column indicates genes without promoter CpG island (MARCO, GLI2) or not analysed (TSN)

methylation at INHBB or EN1 showed a worse overall survival, although the differences were only statistically significant for INHBB and when the methylation status of both promoters was combined, in which case differences were more prominent (Figure 3).

\section{Detection of EN1 methylation as a diagnostic tool in colorectal cancer}

The elevated methylation frequencies of EN1 in colorectal adenomas and carcinomas lead us to evaluate its possible application as a diagnostic marker of colorectal cancer. We determined the methylation status of EN1 CpG island in the DNA obtained from stools, serum and the corresponding tumour samples in an independent series of 30 colorectal cancer patients. Stools and serum DNA obtained from 30 healthy individuals paired by age and sex were used as control group. We applied different techniques to determine the methylation status, namely direct bisulfite sequencing (BS), analysis of MCs and methylation-specific PCR (MSP) (Supplementary Figure 4). To determine the true positive and false positive obtained with each technique, the result obtained from the stool or serum DNA was compared with that from the respective tumour using the same technique. Full data set is provided in Supplementary Figures 5-9 and Supplementary Tables 5 and 6. 

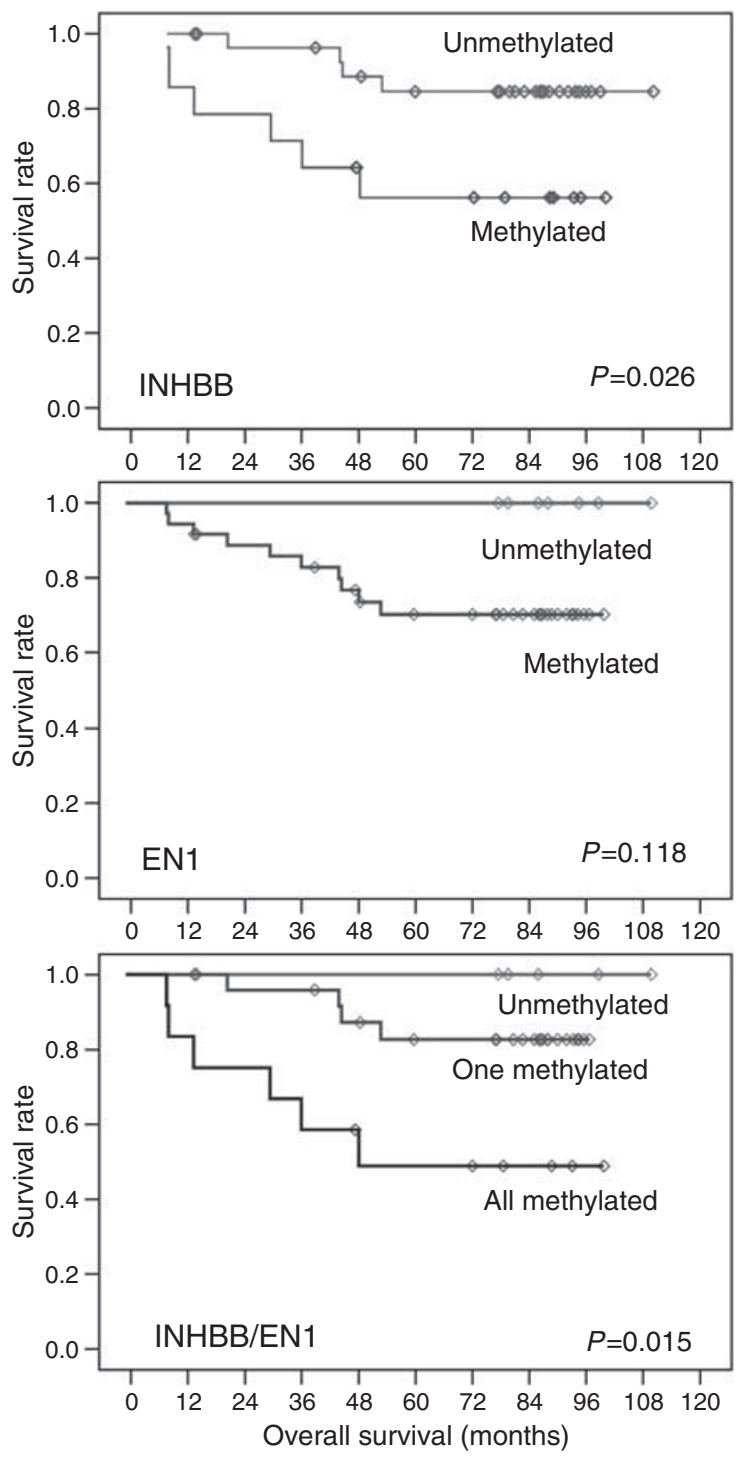

Figure 3 Overall survival in colorectal cancer patients according to the methylation status of INHBB and ENI. Tumours with methylated INHBB or ENI showed a reduced survival rate, but differences reached only statistical significance for INHBB or the combination of both, INHBB and ENI.

Samples exhibiting $\geqslant 25 \%$ methylation (depicted as light grey in figures) in at least half of the analysed CpG sites or $\geqslant 50 \%$ methylation (depicted as dark grey dots in figures) in at least $1 / 4$ of the analysed CpG sites were considered as methylated. MC analysis appeared as the most efficient method to detect EN1 methylation in stool DNA with a sensitivity of $44 \%$ (8 out of 18 ) and $27 \%$ (8 out of 30) considering patients with methylated tumours or all patients, respectively (Figure 4 and Supplementary Table 5). In patients with methylation in the tumours, $17 \%$ (3 out of 17) were detected by bisulfite sequencing and $14 \%$ (4 out of 27 ) by MSP. In serum, the sensitivity of MC analysis was lower ( 2 out of $18,11 \%$ ). All samples from healthy donors were unmethylated as determined by MC analysis but with a single exception in one stool DNA. Bisulfite sequencing of this sample showed full methylation in three CpGs and full unmethylation in the rest of $\mathrm{CpG}$ sites. As two of these methylated $\mathrm{CpG}$ sites were located in the priming region used for MSP analysis, neither methylated nor unmethylated product was obtained using this technique (Figure 4 and Supplementary Table 6). Altogether, MC analysis appears to be
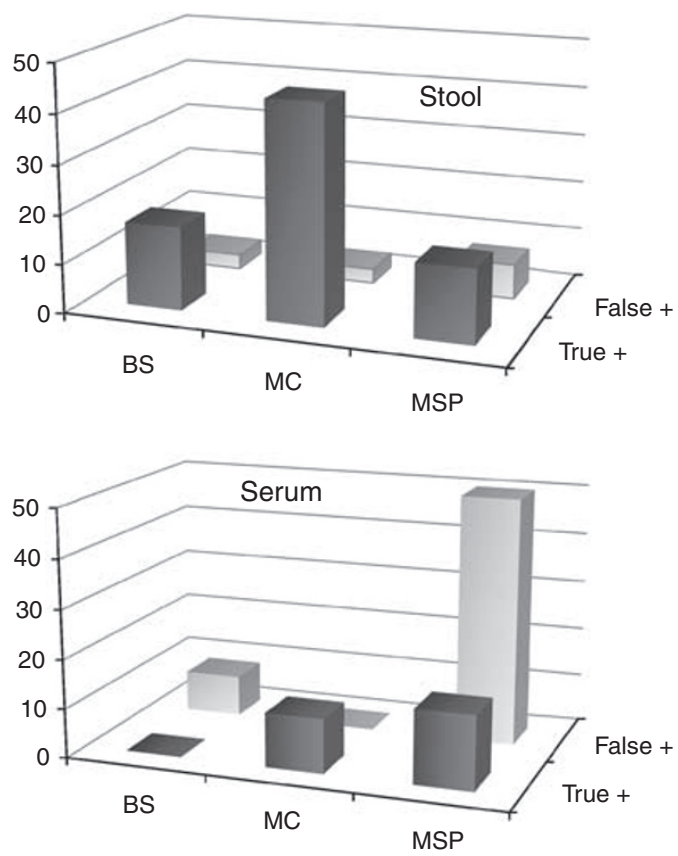

Figure 4 Detection of ENI methylation in stool and serum DNA as a diagnostic marker of colorectal cancer. 'True positive' indicates the percentage of all colorectal cancer patients with a methylated marker in both the tumour and the test sample (stool or serum DNA). 'False positive' corresponds to the percentage of healthy individuals with a methylated result in the test sample. The best score was obtained when melting curve (MC) analysis was applied to detect ENI methylation in stool DNA (27\% of overall sensitivity, $44 \%$ sensitivity in positive tumours, and $97 \%$ specificity).

the most accurate method to detect the presence of EN1 methylation in stool DNA.

\section{DISCUSSION}

Here we report the high prevalence of coordinated epigenetic silencing at 2q14.2 in most if not all colorectal carcinomas. We also show that hypermethylation is an early event that can be selected for during tumourigenesis. This is in concordance with studies at genomic level showing the accumulation of hypermethylation during tumour progression (Toyota et al, 1999; Frigola et al, 2005). The commonness of LRES in colorectal cancer has been confirmed in independent studies, that have also noted the association between hypermethylation of the genes in the 2 q14.2 region and other CpG islands (Karpinski et al, 2008).

The gene expression down-regulation in tumour affected all genes, irrespectively of the presence of $\mathrm{CpG}$ island or the methylation status, confirming the earlier results obtained in cell lines and pooled normal and tumour DNAs (Frigola et al, 2006). The suppression of $2 \mathrm{q} 14.2$ in all the tumours analysed stresses its high prevalence in colorectal cancer. Moreover, the lack of association with DNA methylation suggests that the latter is a secondary phenomenon (Mutskov and Felsenfeld, 2004; Stirzaker et al, 2004; Strunnikova et al, 2005). The arbitrary distribution of DNA methylation along the methylatable CpG islands (Supplementary Figure 3) is also consistent with a model in which regional suppression is followed by spurious DNA methylation of silenced CpG islands showing appropriate epigenetic signatures (Stirzaker et al, 2004). It is of note that some of the genes exhibited wide variations in their expression levels in normal colonic mucosa. This implies that contaminating non-tumour cells may mask 
the downregulation in tumour samples and, hence, microdissection is critical to obtain a precise assessment of differential expression.

The methylation state of the gene promoters did not seem to be associated with clinicopathological or genetic features of the tumours. Some trends were observed, but of little significance and might result from the performance of multiple statistical tests. The large prevalence of gene suppression across $2 \mathrm{q} 14.2$ and the limited accuracy of $\mathrm{CpG}$ island hypermethylation as a surrogate marker of gene silencing seem to hinder this study. Therefore, the implications of this alteration in colorectal cancer remain unknown and future studies at cellular level are required to determine its causes and consequences. On the other hand, the possible association of EN1 and INHBB methylation with worse outcome in early stages of the disease deserves further investigation, as it might have a prognostic value in a subgroup of patients that may benefit from more aggressive therapies.

DNA testing in non-invasive samples seems to be a feasible approach that can complement and probably outperform other screening tests for colorectal cancer (Dong et al, 2001; Ahlquist, 2002; Traverso et al, 2002), although its routine clinical application is still under debate (Brenner and Rennert, 2005; Capella, 2005). De novo DNA methylation in multiple CpG islands is a common event in cancer and a large number of new tumour biomarkers have appeared as promising candidates (Esteller, 2007b). Detection of CpG island methylation in human DNA isolated from stool (Belshaw et al, 2004; Leung et al, 2004; Chen et al, 2005; Zitt et al, 2007) or serum (Zou et al, 2002; Leung et al, 2005; Nakayama et al, 2007; Lofton-Day et al, 2008) has been proposed as a new strategy for the early diagnosis of colorectal neoplasia. Other studies with comparable series have reported high sensitivities for different methylation markers used alone (Chen et al, 2005; Lenhard et al, 2005; Huang et al, 2007a; Wang and Tang, 2008) or in combination (Leung et al, 2004; Petko et al, 2005; Huang et al, 2007b; Lofton-Day et al, 2008), although a wider application is usually hinder by a limited specificity.

The high prevalence of methylation in EN1 CpG island (three out of every four carcinomas show hypermethylation of this gene) together with its possible functional role in cancer (Bachar-Dahan et al, 2006; Rauch et al, 2007) lead us to evaluate its putative clinical usefulness as a diagnostic marker of disease. Of the three techniques used, MSP seems to be extremely sensitive but results in a high rate of positive results in healthy subjects. MC analysis appeared as the best alternative based on its simplicity and performance: $97 \%$ specificity and $44 \%$ sensitivity in patients with a methylated EN1 in the tumour. This corresponds to a $27 \%$ overall sensitivity when non-informative patients (showing unmethylated EN1 in the tumour) are considered. As shown in dilution experiments (Supplementary Figure 2), dissociation temperatures for partially methylated DNA can be distinguished from unmethylated DNA even when just a fraction $(10 \%)$ of the cells show methylation. Although the short number of cases analysed precludes a definitive conclusion, the diagnostic utility of EN1 methylation by itself or as part of a panel of biomarkers deserves further consideration and evaluation in large series of cases.

In summary, our study shows the high prevalence of epigenetic suppression along $2 \mathrm{q} 14.2$ in colorectal cancer. This suppression is manifested in biopsied tumour samples as global downregulation of all the genes mapping to this region and DNA methylation of several CpG islands as a likely secondary event. These observations confirm that long-range epigenetic silencing across $2 \mathrm{q} 14.2$ is a feature of most colon cancers. Finally, the high prevalence of EN1 $\mathrm{CpG}$ island methylation makes this alteration a good candidate as a non-invasive early diagnostic target. Our preliminary analysis indicates the feasibility of the detection of methylated EN1 promoter in stool DNA as a marker of disease.

\section{ACKNOWLEDGEMENTS}

We thank Harvey Evans for revising the manuscript. RM was a FPI fellow of the Spanish Ministry of Science and Innovation. This work was supported by grants from the Spanish Ministry of Science and Innovation (SAF2006/351, SAF2008/1409 and Consolider-Ingenio 2010 CSD2006-49) and Fondo de Investigación Sanitaria (FIS 00/0021 and FIS 05/1006).

Supplementary Information accompanies the paper on British Journal of Cancer website (http://www.nature.com/bjc)

\section{REFERENCES}

Ahlquist DA (2002) Stool-based DNA tests for colorectal cancer: clinical potential and early results. Rev Gastroenterol Disord 2(Suppl 1): S20 - S26

Bachar-Dahan L, Goltzmann J, Yaniv A, Gazit A (2006) Engrailed-1 negatively regulates beta-catenin transcriptional activity by destabilizing beta-catenin via a glycogen synthase kinase-3beta-independent pathway. Mol Biol Cell 17: 2572-2580

Baylin SB (2005) DNA methylation and gene silencing in cancer. Nat Clin Pract Oncol 2(Suppl 1): S4-S11

Belshaw NJ, Elliott GO, Williams EA, Bradburn DM, Mills SJ, Mathers JC, Johnson IT (2004) Use of DNA from human stools to detect aberrant $\mathrm{CpG}$ island methylation of genes implicated in colorectal cancer. Cancer Epidemiol Biomarkers Prev 13: $1495-1501$

Brenner DE, Rennert G (2005) Fecal DNA biomarkers for the detection of colorectal neoplasia: attractive, but is it feasible? J Natl Cancer Inst 97: $1107-1109$

Capella G (2005) Is fecal DNA testing superior to fecal occult-blood testing for colorectal cancer screening? Nat Clin Pract Oncol 2: 234-235

Castells A, Puig P, Mora J, Boadas J, Boix L, Urgell E, Sole M, Capella G, Lluis F, Fernandez-Cruz L, Navarro S, Farre A (1999) K-ras mutations in DNA extracted from the plasma of patients with pancreatic carcinoma: diagnostic utility and prognostic significance. J Clin Oncol 17: $578-584$

Chen WD, Han ZJ, Skoletsky J, Olson J, Sah J, Myeroff L, Platzer P, Lu S, Dawson D, Willis J, Pretlow TP, Lutterbaugh J, Kasturi L, Willson JK, Rao JS, Shuber A, Markowitz SD (2005) Detection in fecal DNA of colon cancer-specific methylation of the nonexpressed vimentin gene. J Natl Cancer Inst 97: 1124-1132

Dong SM, Traverso G, Johnson C, Geng L, Favis R, Boynton K, Hibi K, Goodman SN, D'Allessio M, Paty P, Hamilton SR, Sidransky D, Barany F, Levin B, Shuber A, Kinzler KW, Vogelstein B, Jen J (2001) Detecting colorectal cancer in stool with the use of multiple genetic targets. J Natl Cancer Inst 93: 858-865

Esteller M (2007a) Cancer epigenomics: DNA methylomes and histonemodification maps. Nat Rev Genet 8: 286-298

Esteller M (2007b) Epigenetic gene silencing in cancer: the DNA hypermethylome. Hum Mol Genet 16(Spec No 1): R50-R59

Feinberg AP, Tycko B (2004) The history of cancer epigenetics. Nat Rev Cancer 4: $143-153$

Frigola J, Sole X, Paz MF, Moreno V, Esteller M, Capella G, Peinado MA (2005) Differential DNA hypermethylation and hypomethylation signatures in colorectal cancer. Hum Mol Genet 14: 319-326

Frigola J, Song J, Stirzaker C, Hinshelwood RA, Peinado MA, Clark S (2006) Epigenetic remodeling in colorectal cancer results in coordinate gene suppression across an entire chromosome band. Nat Genet 38: 540-549

Gonzalez-Garcia I, Moreno V, Navarro M, Marti-Rague J, Marcuello E, Benasco C, Campos O, Capella G, Peinado MA (2000) Standardized approach for microsatellite instability detection in colorectal carcinomas. J Natl Cancer Inst 92: 544-549

Hesson LB, Cooper WN, Latif F (2007) Evaluation of the 3p21.3 tumoursuppressor gene cluster. Oncogene 26: 7283-7301 
Hitchins MP, Lin VA, Buckle A, Cheong K, Halani N, Ku S, Kwok CT, Packham D, Suter CM, Meagher A, Stirzaker C, Clark S, Hawkins NJ, Ward RL (2007) Epigenetic inactivation of a cluster of genes flanking MLH1 in microsatellite-unstable colorectal cancer. Cancer Res 67: 9107-9116

Huang Z, Li L, Wang J (2007a) Hypermethylation of SFRP2 as a potential marker for stool-based detection of colorectal cancer and precancerous lesions. Dig Dis Sci 52: 2287-2291

Huang ZH, Li LH, Yang F, Wang JF (2007b) Detection of aberrant methylation in fecal DNA as a molecular screening tool for colorectal cancer and precancerous lesions. World J Gastroenterol 13: 950-954

Karpinski P, Ramsey D, Grzebieniak Z, Sasiadek MM, Blin N (2008) The $\mathrm{CpG}$ island methylator phenotype correlates with long-range epigenetic silencing in colorectal cancer. Mol Cancer Res 6: 585-591

Laird PW (2003) The power and the promise of DNA methylation markers. Nat Rev Cancer 3: 253-266

Lenhard K, Bommer GT, Asutay S, Schauer R, Brabletz T, Goke B, Lamerz R, Kolligs FT (2005) Analysis of promoter methylation in stool: a novel method for the detection of colorectal cancer. Clin Gastroenterol Hepatol 3: $142-149$

Leung WK, To KF, Man EP, Chan MW, Bai AH, Hui AJ, Chan FK, Lee JF, Sung JJ (2004) Detection of epigenetic changes in fecal DNA as a molecular screening test for colorectal cancer: a feasibility study. Clin Chem 50: $2179-2182$

Leung WK, To KF, Man EP, Chan MW, Bai AH, Hui AJ, Chan FK, Sung JJ (2005) Quantitative detection of promoter hypermethylation in multiple genes in the serum of patients with colorectal cancer. Am J Gastroenterol 100: $2274-2279$

Lofton-Day C, Model F, Devos T, Tetzner R, Distler J, Schuster M, Song X, Lesche R, Liebenberg V, Ebert M, Molnar B, Grutzmann R, Pilarsky C, Sledziewski A (2008) DNA methylation biomarkers for blood-based colorectal cancer screening. Clin Chem 54: 414-423

Melki JR, Vincent PC, Clark SJ (1999) Concurrent DNA hypermethylation of multiple genes in acute myeloid leukemia. Cancer Res 59: 3730-3740

Mutskov V, Felsenfeld G (2004) Silencing of transgene transcription precedes methylation of promoter DNA and histone $\mathrm{H} 3$ lysine 9. EMBO J 23: $138-149$

Nakayama G, Hibi K, Kodera Y, Koike M, Fujiwara M, Nakao A (2007) P16 methylation in serum as a potential marker for the malignancy of colorectal carcinoma. Anticancer Res 27: 3367-3370

Petko Z, Ghiassi M, Shuber A, Gorham J, Smalley W, Washington MK, Schultenover S, Gautam S, Markowitz SD, Grady WM (2005) Aberrantly methylated CDKN2A, MGMT, and MLH1 in colon polyps and in fecal DNA from patients with colorectal polyps. Clin Cancer Res 11: $1203-1209$
Puig P, Urgell E, Capella G, Villanueva A, Grau M, Sancho FJ, Pujol J, Lluis F, Gonzalez-Sastre F, Mora J (1999) Improved detection of $\mathrm{K}$-ras codon 12 mutations in fecal exfoliated cells. Lab Invest 79: 617-618

Rauch T, Wang Z, Zhang X, Zhong X, Wu X, Lau SK, Kernstine KH, Riggs AD, Pfeifer GP (2007) Homeobox gene methylation in lung cancer studied by genome-wide analysis with a microarray-based methylated CpG island recovery assay. Proc Natl Acad Sci USA 104: $5527-5532$

Rodriguez J, Muñoz M, Vives L, Frangou CG, Groudine M, Peinado MA (2008) Bivalent domains enforce transcriptional memory of DNA methylated genes in cancer cells. Proc Natl Acad Sci USA 105: 19809-19814

Stirzaker C, Song JZ, Davidson B, Clark SJ (2004) Transcriptional gene silencing promotes DNA hypermethylation through a sequential change in chromatin modifications in cancer cells. Cancer Res 64: 3871-3877

Stransky N, Vallot C, Reyal F, Bernard-Pierrot I, de Medina SG, Segraves R, de Rycke Y, Elvin P, Cassidy A, Spraggon C, Graham A, Southgate J, Asselain B, Allory Y, Abbou CC, Albertson DG, Thiery JP, Chopin DK, Pinkel D, Radvanyi F (2006) Regional copy number-independent deregulation of transcription in cancer. Nat Genet 38: 1386-1396

Strunnikova M, Schagdarsurengin U, Kehlen A, Garbe JC, Stampfer MR, Dammann R (2005) Chromatin inactivation precedes de novo DNA methylation during the progressive epigenetic silencing of the RASSF1A promoter. Mol Cell Biol 25: 3923-3933

Toyota M, Ahuja N, Ohe-Toyota M, Herman JG, Baylin SB, Issa JP (1999) CpG island methylator phenotype in colorectal cancer. Proc Natl Acad Sci USA 96: $8681-8686$

Traverso G, Shuber A, Levin B, Johnson C, Olsson L, Schoetz Jr DJ, Hamilton SR, Boynton K, Kinzler KW, Vogelstein B (2002) Detection of APC mutations in fecal DNA from patients with colorectal tumors. N Engl J Med 346: 311-320

Vendrell E, Morales C, Risques RA, Capella G, Peinado MA (2005) Genomic determinants of prognosis in colorectal cancer. Cancer Lett 221: 1-9

Vendrell E, Ribas M, Valls J, Sole X, Grau M, Moreno V, Capella G, Peinado MA (2007) Genomic and transcriptomic prognostic factors in R0 Dukes $\mathrm{B}$ and C colorectal cancer patients. Int J Oncol 30: 1099-1107

Wang DR, Tang D (2008) Hypermethylated SFRP2 gene in fecal DNA is a high potential biomarker for colorectal cancer noninvasive screening. World J Gastroenterol 14: 524-531

Zitt M, Zitt M, Muller HM (2007) DNA methylation in colorectal cancerimpact on screening and therapy monitoring modalities? Dis Markers 23: $51-71$

Zou HZ, Yu BM, Wang ZW, Sun JY, Cang H, Gao F, Li DH, Zhao R, Feng GG, Yi J (2002) Detection of aberrant p16 methylation in the serum of colorectal cancer patients. Clin Cancer Res 8: 188-191 